\title{
Prevalence of drug resistance in clinical isolates of tuberculosis from GCC: a literature review from January 2002 to March 2013
}

\author{
Mohammed Yahya Areeshi ${ }^{1}$, Shekhar Chandra Bisht ${ }^{2}$, Raju Kumar Mandal ${ }^{1}$, Shafiul Haque ${ }^{1,3}$ \\ ${ }^{1}$ Research and Scientific Studies Unit, College of Nursing and Allied Health Sciences, Jazan University, Jazan, \\ Saudi Arabia \\ ${ }^{2}$ Department of Biotechnology, Hemwati Nandan Bahuguna Garhwal University, Srinagar (Garhwal), Uttarakhand, \\ India \\ ${ }^{3}$ Department of Biosciences, Jamia Millia Islamia (A Central University), New Delhi, India
}

\begin{abstract}
Introduction: The prevalence of drug resistance in clinical isolates of Mycobacterium tuberculosis from the Gulf Cooperation Council (GCC; Saudi Arabia, Qatar, Bahrain, Kuwait, Oman, United Arab Emirates [UAE]) countries was appraised using reports published between January 2002 and March 2013.

Methodology: A total of 11,393 tuberculosis (TB) isolates from the GCC were studied through published literature and were analyzed statistically.

Results: Most of the isolates were resistant to isoniazid, followed by streptomycin, rifampin, ethambutol, and pyrazinamide. The highest prevalence rate of multidrug-resistant-TB (MDR-TB) was found in UAE (9.2\%), followed by Kuwait (5.9\%) and Saudi Arabia (4.3\%). The overall MDR-TB prevalence rate was recorded as $4.0 \%$ in the entire GCC region. Automated linear modeling revealed that isoniazid resistance had a strong relationship with the prevalence of MDR-TB in all the GCC countries and was found to be the strongest predictor for MDR-TB. Interestingly, rifampicin resistance was significantly associated with the prevalence of MDR-TB in Oman, Kuwait, and Saudi Arabia, while isoniazid was identified for UAE. On the basis of a number of reports and isolates, the principal component analysis showed that, among all GCC member countries, the highest burden of TB was in Saudi Arabia and Kuwait, and maximum drug resistance was present in UAE.

Conclusion: The study demonstrates that the prevalence of MDR-TB in GCC countries is almost equal to other developing and developed countries, and requires immediate attention for surveillance and control.
\end{abstract}

Key words: Mycobacterium tuberculosis; TB; drug-resistance; GCC; Gulf countries; MDR-TB.

J Infect Dev Ctries 2014; 8(9):1137-1147. doi:10.3855/jidc.4053

(Received 27 July 2013 - Accepted 23 January 2014)

Copyright $(2014$ Areeshi et al. This is an open-access article distributed under the Creative Commons Attribution License, which permits unrestricted use, distribution, and reproduction in any medium, provided the original work is properly cited.

\section{Introduction}

Tuberculosis (TB) remains a major health problem and causes ill health among millions of people each year. Globally, TB is second leading cause of death from HIV/AIDS. According to the World Health Organization (WHO), the latest estimate suggests that almost 9 million new TB cases and 1.4 million TB deaths were recorded in 2011 [1,2]. TB can usually be treated with a course of four standard, or first-line, anti-TB drugs: isoniazid (INH), rifampicin (RMP), pyrazinamide (PZA), and ethambutol (EMB). If these drugs are misused, multidrug-resistant TB (MDR-TB) can develop [1]. MDR-TB is one of the most dangerous forms of TB; it is defined as tuberculosis that is resistant to at least isoniazid and rifampicin, the two most powerful first-line anti-TB treatment drugs
[3]. MDR-TB takes longer to treat with second-line drugs (SLDs), which are more expensive and have more side effects. MDR-TB develops in otherwise treatable TB when the course of antibiotics is interrupted and the levels of drug in the body are insufficient to kill $100 \%$ of the bacteria. Extensively drug-resistant TB (XDR-TB) is a rare type of MDRTB that is resistant to any fluoroquinolone and at least one of three injectable SLDs in addition to isoniazid and rifampin. XDR-TB can develop when second-line drugs are also misused or mismanaged and therefore also become ineffective. The WHO estimated nearly 270,000 prevalence cases and about 67,500 deaths in the year 2011 due to MDR-TB [1]. The proportion of MDR-TB patients who successfully completed treatment varied from 44\% (Eastern Mediterranean 
region) to $58 \%$ (South-East Asia region). Overall treatment success was $48 \%$, whereas $28 \%$ of cases were reported as lost to follow-up or had no information regarding their outcomes [1]. Al-Hajoj et al. (2013) reported that among a subset of 200 XDRTB patients in 14 countries, the overall treatment success was $33 \%$, and $26 \%$ of cases resulted in death, which indicated poor treatment success rate against drug resistance $[1,4]$. Similarly, in the year 2010, 3.4\% of all newly diagnosed and $19.8 \%$ of all previously treated TB cases were evidenced to have MDR-TB [5].

The Gulf Cooperation Council (GCC) is a political, scientific, business, and economic union of the Arab states bordering the Persian Gulf and located on or near the Arabian Peninsula. Presently, six Middle Eastern countries (Bahrain, Kuwait, Oman, Qatar, Saudi Arabia, and United Arab Emirates) are the member states of GCC, and few more are trying to become a part of the GCC [6-8]. In all GCC countries, the real burden of drug-resistant $\mathrm{TB}$ is not known, as these countries (with the exception of Saudi Arabia) have never conducted a representative national-level survey to estimate the prevalence and patterns of anti-TB drugresistance [4].

Based on modeling work, WHO estimated that $1.2 \%$ (range $0.7 \%-1.6 \%$ ) and $9.0 \%$ (range $5.6 \%-$ $12.4 \%$ ) of new and previously treated cases, respectively, had MDR-TB [9]. A few small-scale studies were conducted in Saudi Arabia and reported that proportions of resistance to any first-line drugs were in the range of $14 \%$ to $20 \%$, and for MDR-TB were in the range of $1 \%$ to $44 \%[4,10]$. These findings must be treated with full caution, as these studies were not representative of the entire country, and most were retrospective analyses of laboratory results collected from hospitals, medical colleges, and primary healthcare centers. The compositions of the populations of all GCC countries are unique for two reasons: nearly one-third of their population are immigrant workers, and in Saudi Arabia, nearly 10 million foreigners visit the country every year for Islamic rituals (i.e., Hajj and Umrah) [10]. It has already been established that the epidemiology of TB infection is clearly influenced by immigration and mass gatherings $[4,10]$. Few review articles studying the prevalence rates of drug-resistant TB were published from Saudi Arabia. No authentic report is available in the English language about the prevalence of drug-resistant TB in other GCC countries. Thus, a systematic review covering a 12-year period starting from January 2002 to March 2013 of published reports and peer-reviewed articles relating to prevalence and MDR-TB in six current GCC member countries was conducted. In addition to tracking the prevalence of TB and the occurrence of multidrug-resistant strains, the present study aimed to evaluate the status of TB infection, the extent of drug-resistant-TB, and the identification of possible predictors for the detection of MDR-TB in the current GCC countries. This would be helpful for the development of novel control and management strategies that can be used to combat the menace of drug-resistant $M$. tuberculosis.

\section{Methodology}

Identification, eligibility, and inclusion of relevant studies

A selective literature review was conducted using the PubMed (Medline), EMBASE, and Google Scholar web databases. The search was limited to the English language. Important key words and phrases used for the search were: tuberculosis; drug-resistant tuberculosis; prevalence of tuberculosis; antituberculosis drug-resistance; names of commonly used drugs to treat TB (i.e., isoniazid, rifampicin, pyrazinamide, ethambutol, streptomycin); names of the GCC countries, cities, provinces, or states (i.e., Saudi Arabia, Qatar, Bahrain, Kuwait, Doha, Oman, UAE, Dubai, Sharjah, Ajman, Muscat, Abu Dhabi, Jeddah, Makkah, and Riyadh); Gulf countries; Middle Eastern countries; and a few more combinations of country names. Articles published in last twelve years (1st January 2002 to 31st March 2013) were included in this study.

\section{Inclusion and exclusion criteria}

In order to reduce heterogeneity and ease the appropriate interpretation and understanding of the current study, articles incorporated in this study were directly relevant to the selected topic based on epidemiological, clinical, and policy standpoints. Studies focusing exclusively on drug discovery, drug chemistry, drug toxicology, or diagnostic comparison were excluded, except for those that identified drug resistance or appraised differences between population groups to describe variances in the prevalence of $\mathrm{TB}$ drug- resistance. Inclusion of reports was further stratified and limited to only those conducted in last 12 years. Individual case reports and general reviews were also excluded. Appropriate reference articles were also included in the summary. A total of 28 articles were finally included in the summary (Figure 1). 


\section{Data extraction and quality assessment}

Each selected study was evaluated using the present study's aim: to estimate the distribution of drug-resistant TB in GCC member states. The retrieved studies were examined by the research theme, which included abstract, literature review, research methodology, major outcomes, the study setting, and the country where the study was performed. Important objectives and outcomes were identified for each study. For articles in which themes were explicitly reported, they were noted precisely. However, for articles were no theme was presented, implicit and reasonable themes were generated based on the overall findings of the study. During the article selection process, seven studies were explicitly excluded, as all included GCC countries' data along with some other undesired information; one report presented aggregate data from other countries in addition to the other GCC countries, making it impractical to separate data for individual countries, and other studies were excluded because of their nonhospital base, method validation, or diagnostic nature.

\section{Statistical analysis}

Statistical data analysis was performed using the statistical program SPSS (version 21.0), and descriptive statistics were utilized to express the findings. Generated data was processed and the weighted mean was estimated by the estimated marginal mean function of SPSS. Outcomes and data were expressed as numbers (n) and percentages (\%). Drug resistance data for all the GCC member states were converted into percentages and analyzed statistically by analysis of variance (ANOVA) using SPSS, and the treatment means were separated according to one-way ANOVA using Duncan's multiple-range test (DMRT) function. For all variables taken into account, probabilities of less than 0.05 were considered to be statistically significant. An automated linear modeling analysis, using forward stepwise with adjusted R2 selection (standard model) was employed to predict the relationships and to evaluate the effect of each individual drug's resistance on MDR-TB. Linear modeling was performed to select the most effective model that could explain the correlation and effect between the independent and the dependent variables. To determine the grouping pattern of the GCC countries based on the drug resistance for individual country, principal component analysis (PCA) was performed using an average of total drug-resistance data along with individual GCC country. All variables (i.e. total number of isolates, total retrieved reports,
Figure 1. Flow diagram showing the selection of the studies included in the present analysis: total articles published in the English language identified by the search.

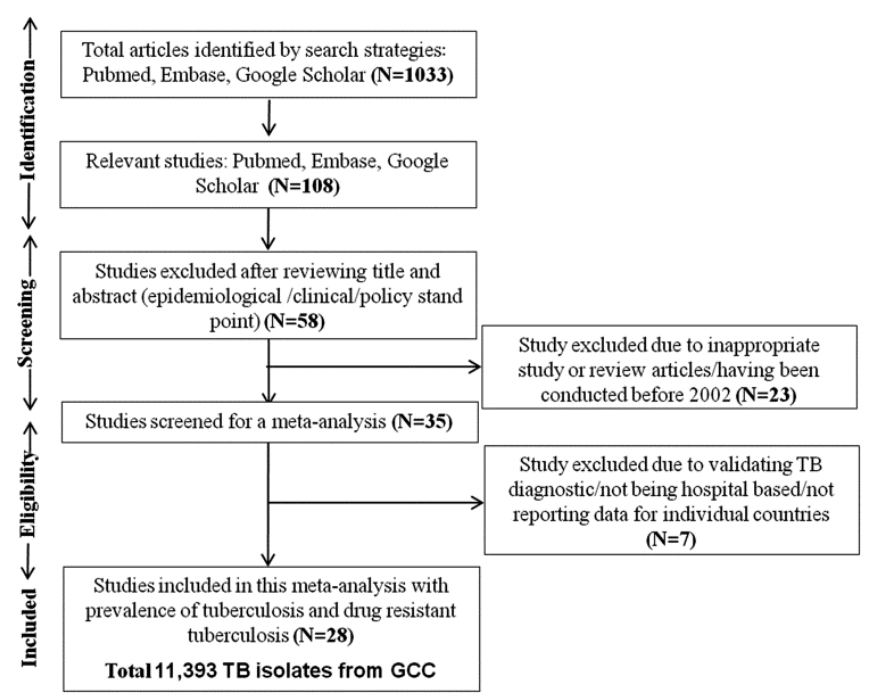

and data for the mean rate [\%] for each [mono] drugresistance) were selected and PCA was done using the XLSTAT program (XLSTAT, version 2013).

\section{Results}

Characteristics of the published studies

A total of 1,033 English-language articles were retrieved through a selective literature search from the PubMed (Medline), EMBASE, and Google Scholar web databases. All retrieved articles were inspected by reading the titles, abstracts, and full texts of the potentially relevant publications. In addition to the database search, the references listed in the retrieved publications were also screened for other potential studies (Figure 1). Only hospital-based and confirmed TB cases were included in this study. Studies based on diagnostic tests or studies that did not clarify the actual number of cases or isolates were excluded straightaway. To avoid repeatability of the data, review articles on prevalence and anti-tuberculosis were also excluded. Studies based on the prevalence of tuberculosis and drug-resistant TB conducted in GCC countries only were considered for this study. Following the above criteria, out of 1,033 articles, only 108 were found to be unique. However, when the search was restricted to articles published between January 2002 and March 2013, only 58 unique articles remained. 
Table 1. Details of published studies in English language from the GCC countries dealing with prevalence of TB drug-resistance

\begin{tabular}{|c|c|c|c|c|c|c|c|c|c|c|}
\hline \multirow[t]{2}{*}{ Study No. } & \multirow{2}{*}{$\begin{array}{c}\text { Total } \\
\text { isolates }\end{array}$} & \multicolumn{7}{|c|}{ Drug resistance (No. of isolates) } & \multirow{2}{*}{ Year } & \multirow{2}{*}{ References } \\
\hline & & RMP & INH & STR & EMB & FLU & PZA & MDR-TB & & \\
\hline \multicolumn{11}{|l|}{ [a] Qatar } \\
\hline 1 & 1193 & -- & -- & -- & -- & -- & -- & -- & 2005 & Al-Khal et al. [23] \\
\hline 2 & 35 & -- & -- & -- & -- & -- & -- & -- & 2009 & Khan [24] \\
\hline 3 & 54 & -- & -- & -- & -- & - & -- & -- & 2012 & Khan et al. [25] \\
\hline Total $=3$ & 1282 & -- & -- & -- & - & -- & -- & - & -- & -- \\
\hline \multicolumn{11}{|l|}{ [b] Oman } \\
\hline 1 & 1116 & -- & -- & -- & -- & -- & -- & -- & 2007 & Al-Maniri et al. [26] \\
\hline 2 & 13 & 5 & 5 & 3 & 1 & -- & 2 & 13 & 2008 & Mohammadi et al.[27] \\
\hline 3 & 312 & 2 & 21 & -- & -- & -- & -- & 2 & 2010 & Al-Maniri et al. [28] \\
\hline Total $=3$ & 1441 & 7 & 26 & 3 & 1 & -- & 2 & 15 & -- & -- \\
\hline \multicolumn{11}{|l|}{ [c] Kuwait } \\
\hline 1 & 38 & -- & 38 & -- & -- & -- & -- & -- & 2002 & Mokaddas et al. [29] \\
\hline 2 & 53 & 32 & -- & -- & -- & -- & -- & -- & 2005 & Ahmad and E. Mokaddas, [30] \\
\hline 3 & 152 & -- & 3 & -- & 50 & -- & -- & -- & 2007 & Ahmad et al. [31] \\
\hline 4 & 55 & 35 & 35 & -- & -- & -- & -- & 35 & 2008 & Al-Mutairi et al. [32] \\
\hline 5 & 2383 & 28 & 211 & 113 & 56 & -- & -- & 23 & 2008 & Mokaddas et al. [33] \\
\hline 6 & 75 & 12 & 39 & 14 & 50 & -- & -- & 3 & 2009 & Jaber et al.[34] \\
\hline 7 & 125 & 82 & 82 & -- & -- & -- & -- & 82 & 2011 & Al-Mutairi et al.[35] \\
\hline 8 & 226 & 119 & -- & -- & -- & -- & -- & -- & 2012 & Ahmad et al.[36] \\
\hline Total $=8$ & 3107 & 308 & 408 & 127 & 156 & -- & -- & 183 & -- & $-{ }^{2}-$ \\
\hline \multicolumn{11}{|l|}{ [d] UAE } \\
\hline 1 & 28 & 4 & 10 & 4 & 3 & -- & -- & 4 & 2002 & Ahmad et al. [16] \\
\hline 2 & 32 & 11 & 32 & 9 & 15 & -- & -- & 11 & 2005 & Ahmad and Fares, [37] \\
\hline 3 & 32 & -- & -- & -- & 17 & -- & -- & -- & 2008 & Ahmad et al. [38] \\
\hline 4 & 312 & 12 & 66 & 34 & 28 & -- & -- & 15 & 2010 & Al-Zarouni et al. [39] \\
\hline 5 & 43 & 14 & 15 & 11 & 9 & -- & 15 & 11 & 2010 & Saif Al-faresi and Hag-Ali, [40] \\
\hline Total $=5$ & 447 & 42 & 123 & 58 & 72 & -- & 15 & 41 & -- & -- \\
\hline \multicolumn{11}{|c|}{ [e] Saudi Arabia } \\
\hline 1 & 764 & 21 & 54 & 29 & 12 & -- & -- & 19 & 2004 & Kordy et al. [41] \\
\hline 2 & 276 & 35 & 3 & 19 & 21 & -- & -- & 2 & 2005 & Al-Tawfiq et al. [42] \\
\hline 3 & 16 & 1 & 1 & 1 & 1 & -- & -- & 1 & 2007 & Al-Anazi et al. [43] \\
\hline 4 & 1,505 & 50 & 50 & 18 & 1 & -- & -- & 50 & 2007 & Al-Hajoj et al. [44] \\
\hline 5 & 1 & 1 & 1 & -- & 1 & -- & -- & 1 & 2007 & Al-Shehri et al. [45] \\
\hline 6 & 431 & -- & -- & -- & -- & -- & -- & -- & 2010 & Al-Otaibi et al. [46] \\
\hline 7 & 68 & 16 & 23 & 9 & 2 & -- & -- & 14 & 2012 & Asaad and Alqahtani, [47] \\
\hline 8 & 151 & 59 & 75 & -- & -- & -- & -- & 59 & 2012 & Varghese et al. [48] \\
\hline 9 & 1904 & 101 & 239 & 285 & 158 & -- & -- & 76 & 2013 & Al-Hajoj et al. [4] \\
\hline Total $=9$ & 5116 & 449 & 449 & 361 & 216 & -- & -- & 222 & -- & -- \\
\hline
\end{tabular}

Note: RMP: Rifampicin; INH: Isoniazid; STR: Steptomycin; EMB: Ethambutol; FLU: Fluoroquinolones; PZA: Pyrazinamide; MDR: Multi drug-resistance 
Table 2. The prevalence of drug-resistance in TB isolates from the GCC countries

\begin{tabular}{|c|c|c|c|c|c|c|c|c|c|}
\hline \multirow{2}{*}{ GCC country } & \multirow{2}{*}{$\begin{array}{l}\text { No. of reports in } \\
\text { the English } \\
\text { language }\end{array}$} & \multirow{2}{*}{$\begin{array}{c}\text { Total isolates/ } \\
\text { patients }(\%)\end{array}$} & \multicolumn{7}{|c|}{ Drug resistance [No. of isolates $(\%)]$} \\
\hline & & & RMP & INH & STR & EMB & FLU & PZA & MDR-TB \\
\hline Bahrain & - & - & - & - & - & - & - & - & - \\
\hline Qatar & $3(11.1)$ & $1282(11.3)$ & - & - & - & - & - & - & - \\
\hline Oman & $3(11.1)$ & 1441 (12.6) & $7(0.5)$ & $26(1.8)$ & $3(0.2)$ & $1(0.1)$ & - & $2(0.1)$ & $15(1.0) \mathrm{a}$ \\
\hline Kuwait & $8(29.6)$ & $3107(27.3)$ & $308(9.9) b$ & $408(13.1) b$ & $127(4.1) \mathrm{a}$ & $156(5.0) \mathrm{b}$ & 0 & 0 & $183(5.9) \mathrm{c}$ \\
\hline UAE & $5(18.6)$ & 447 (3.9) & $42(9.4) b$ & $123(27.5) \mathrm{c}$ & $58(13.0) \mathrm{c}$ & $72(16.1) \mathrm{c}$ & 0 & $15(3.4)$ & $41(9.2) \mathrm{d}$ \\
\hline Saudi Arab & $9(33.3)$ & $5116(44.9)$ & $252(4.9) \mathrm{a}$ & $478(9.3) \mathrm{a}$ & $364(7.1) b$ & $216(4.2) \mathrm{a}$ & 0 & $17(0.001)$ & $222(4.3) b$ \\
\hline Total & 28 & 11393 & $609(5.3 \%)$ & $1035(9.1 \%)$ & $552(4.8 \%)$ & 445 (3.9\%) & $0(0.0 \%)$ & $34(0.3 \%)$ & $461(4.0 \%)$ \\
\hline
\end{tabular}

Note: (i) RMP: Rifampicin; INH: Isoniazid; STR: Steptomycin; EMB: Ethambutol; FLU: Fluoroquinolones; PZA: Pyrazinamide; MDR: Multi drug-resistance; SDR: Single drug-resistance (ii) Values followed by different alphabetical letters in the same column indicate significant difference $(\mathrm{P}<0.05)$ according to DMRT analysis. 
A comprehensive review of the titles and abstracts of the retrieved articles left 35 articles that examined the prevalence of tuberculosis and drug-resistant TB in GCC countries. Based upon careful screening and by strictly following the inclusion and exclusion criteria, only 28 original published articles were found to be eligible and finally included in the analysis for the current study. The study selection showed that most of the studies were published from Saudi Arabia $(n=9)$, followed by Kuwait $(n=8)$ and $\operatorname{UAE}(n=5)$. Only three studies each were published from Oman and Qatar, and surprisingly, no published studies were available from Bahrain. Table 1 shows the selection summary of reports included in this study.

\section{Prevalence of TB drug resistance}

Between January 2002 and March 2013, there were 28 articles published addressing TB prevalence and drug-resistant TB in the GCC member states. However, out of these 28 articles, only 5 addressed the prevalence of tuberculosis. Out of these 5 studies, 3 were conducted in Qatar, 1 study was published from Saudi Arabia, and 1 from Oman. Results showed that the highest number of studies were reported from Saudi Arabia (9 out of 28; 33.3\%), followed by Kuwait ( 8 out of $28 ; 29.6 \%$ ) and UAE ( 5 out of 28 ; $18.6 \%)$. No report published from Bahrain according to the preset selection criteria was retrieved; even a simple search performed through Google failed to retrieve a single report. All 28 unique articles were analyzed critically, as they contained national-level data. Among all the GCC member states, a total of 11,393 TB isolates were analyzed, while 8,564 isolates were studied for TB drug resistance. The isolates and their respective drug resistance(s) were distributed in different GCC member states as listed in Tables 1 and 2. Data gathered on drug resistance of M. tuberculosis from all GCC states demonstrated marked variations depending on the country's geographical location, immigration rate, and social culture. The highest MDR-TB prevalence rate was noted for UAE $(9.2 \%)$, followed by Kuwait (5.9\%) and Saudi Arabia (4.3\%), whereas a low prevalence rate was observed in Oman (1\%) (Table 2). The maximum numbers of TB drugresistant isolates were reported from Saudi Arabia $(\mathrm{n}=$ $222)$, followed by Kuwait $(n=183)$ and $\operatorname{UAE}(n=41)$ (Table 2). Overall MDR-TB prevalence was estimated for all the GCC states; it was found to be $4.0 \%$ of the total TB infection.

High levels of TB drug resistance were reported from UAE; their drug resistance patterns are shown in Table 2 . Resistance to pyrazinamide was only reported from UAE. Following the UAE, resistance to isoniazid and rifampicin was reported from Kuwait (13.1\%, 9.9\%, respectively) and Saudi Arabia (9.3\%, 4.9\%, respectively) among all the GCC countries. The greatest resistance against ethambutol was recorded for the isolates reported from UAE (16.1\%), followed by Kuwait (5\%) and Saudi Arabia (4.2\%) (Table 2). It was noted that the overall prevalence of $\mathrm{TB}$ drug resistance in all the GCC member countries was highest to the first-line TB drugs. The order of drug resistance in GCC was isoniazid, streptomycin, rifampicin, ethambutol, and pyrazinamide (Table 2). The mean values of drug resistance were derived and compared, and significant differences for each country in terms of prevalence were demonstrated statistically. Since there were no authentic reports on TB drug resistance in the last 12 years from Qatar and Bahrain, the precise rate of $\mathrm{TB}$ drug resistance in these two GCC countries could not be predicted.

\section{Multivariate analysis}

Automated linear modeling (ALM) was performed to evaluate the relationship and effect of each individual drug's resistance on the prevalence of MDR-TB. ALM was done using a standard model to explain the relationships between MDR and prominent drug. Standard models are easier to interpret and can be faster to score than boosted, bagged, or large dataset ensembles. Due to the low number of rows (i.e., published reports from each country), it was not possible to employ linear modeling analysis. Hence, an alternative and logical statistical analysis tool was used to evaluate the association. The model contained the most important predictor (drug) for possible causes of MDR-TB. All models were statistically significant ( $\mathrm{p}<0.05$ ), and showed $40 \%$ to $70 \%$ accuracy. As presented in Figure 2A, only one significant $(\mathrm{p}=$ 0.000 ) predictor (i.e., rifampicin) was identified for MDR-TB in Oman. Interestingly, rifampicin was found to be a less significant ( $\mathrm{p}=0.043)$ MDR-TB predictor for Kuwait and highly significant $(p=0.001)$ for Saudi Arabia (Figures 2B, 2D). Isoniazid was found to be the strongest predictor (most significant, $\mathrm{p}$ $=0.000$ ) for MDR-TB in UAE (Figure 2C). Hence, it can be assumed that TB isolates from UAE, which were resistant to isoniazid, will have more chances of conversion into MDR-TB or already have MDR-TB. Analysis of all the GCC countries showed two main predictors for prevalence of MDR-TB - isoniazid and rifampicin (Figure 2E). The isoniazid drug resistance $(p=0.013)$ was found to be the strongest predictor for MDR-TB in all the GCC countries. Modeling analysis 
indicated that those TB isolates which were found resistant to isoniazid would have a $63.6 \%$ higher chance of conversion into MDR-TB, could already have MDR-TB, or would be identified as MDR-TB. Rifampicin resistance was predicted as a $36.4 \%$ contributing factor for MDR-TB for all the GCC countries (Figure 2).

The PCA study grouped the GCC countries based on the TB prevalence and $\mathrm{TB}$ drug resistance, and indicated a clear relationship between drug resistance and respective GCC country (Figure 3). The first two factorial axes represented $97.48 \%$ variance of the data included in the present study. Factor F1 represented the grouping of the TB prevalence and number of publications; factor F2 represented the grouping based on drug resistance and included strong predictors of
MDR - ethmbutol followed by isoniazid (Figure 3A). However, those predictors that did not contribute to the model were placed in the middle of both the factors and showed no correlation. The countries placed at the strong positive side of factor F1 showed high prevalence of drug resistance and included UAE followed by Kuwait and Saudi Arabia (Figure 3B). On the other hand, those countries that were placed at the more positive axis of factor F2 indicated high prevalence of TB and included Kuwait and Saudi Arabia. Three GCC countries (Oman, Qatar, Bahrain) were found to be on the negative side of both factors (F1 and F2) and had lower prevalence of TB and drug resistance. Due to lack of a sufficient number of isolates or reports from Bahrain and Qatar, a significant conclusion could not be reached.
Figure 2. Relationship/effect of TB drug resistance with MDR-TB for the selected individual GCC country/all GCC countries (automated linear model $[95 \%$ $\mathrm{CI}]$ ).
Figure 3. PCA for the distribution of all the GCC countries based on drugresistance profile. Factor map of rows (GCC countries) with similar distributions of appearance with high prevalence of drug resistance occurs in similar positions on the map, while positions of some countries showed no or less prevalence of TB drugresistance.

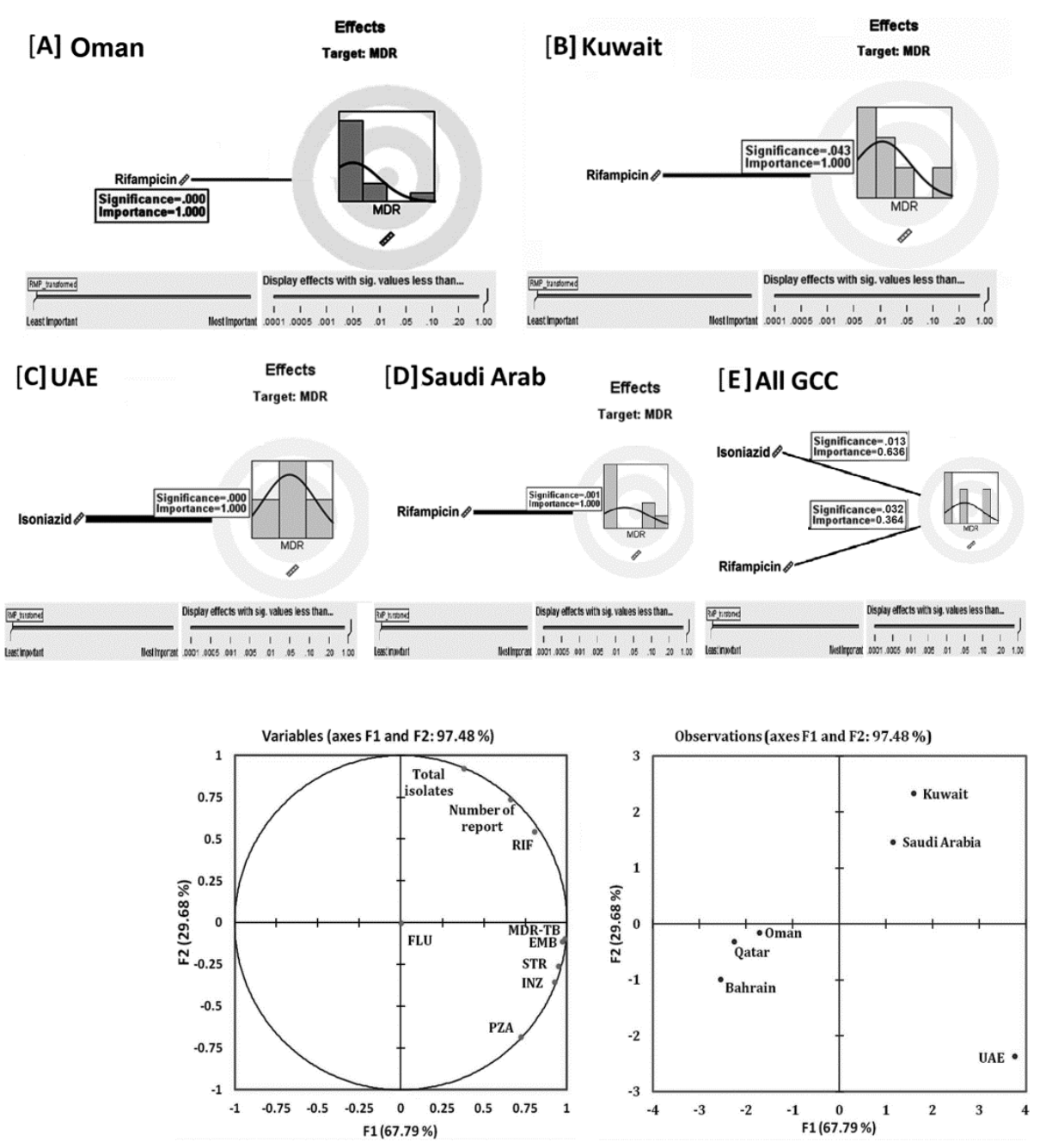




\section{Discussion}

To cope with the increased menace of MDR-TB, the WHO updated its guidelines in 2011 for the programmatic management of drug-resistant TB. After reviewing and analyzing the data, we found that most of the reports related to the prevalence of MDR-TB in the GCC countries were from Saudi Arabia, Kuwait, and UAE (Table 1). Only two pertinent reports were found from Oman, while none from Qatar and Bahrain were found. Even a further Google search showed no such reports in English outside of the PubMed, EMBASE, and Google Scholar web databases. It was strange that many strong reports existed, yet none were published in the English language or in the peerreviewed scientific literature indexed in PubMed and ISI journals, which might pose a question regarding the authenticity of the published data; we thus limited our study selection to the standard scientific English language. No studies provided incidence rates or annual trends or patterns of TB drug resistance from all or from important regions of the nation. The current findings clearly identify the major challenges, which include the gathering of reliable data, periodical follow-up regarding the prevalence of MDR-TB, and the emergence of newer organisms. Based upon these findings, we can suggest that, to tackle this global health threat, drug-resistant TB management requires a well-funded infectious disease surveillance system staffed with well-trained professionals in all GCC member states [10].

In the present study, isoniazid was found to be the strongest predictor for the identification of MDR-TB in all the GCC countries (Figure 2). This finding is in congruence with the rapid detection of MDR-TB through a probe for the $k a t G$ gene available in some countries, which serves as a useful marker for MDRTB because rifampicin resistance is rare (except when patients have a history of being treated with isoniazid/rifampicin alone). In the present study, for each GCC country, this predictor was found to be different; rifampicin resistance was observed to be a significant predictor for the identification of MDR-TB in Oman, Kuwait, and Saudi Arabia. Possibly, isoniazid and rifampicin are potent drugs for the treatment of tuberculosis and are implicated in patient management until microbiological proof that they are ineffective (though isoniazid resistance commonly occurs with rifampicin resistance) [11,12]. Hence, it is obvious that rifampicin should be considered as an MDR-TB predictor for these GCC counties, as most of the MDR-TB isolates were found to be positive for rifampicin resistance. However, isoniazid resistance was found to be the strongest MDR-TB predictor for UAE, as revealed by the significant correlation. This could be possible because most of the rifampicinresistant TB strains from UAE were found to be negative for MDR-TB. Hence, the reliability of this marker is quite high, as the highest number of isoniazid-resistant isolates were also found to be MDR-TB positive. However, due to the insufficient number of TB isolates and reports from UAE, precise conclusions could not be drawn. PCA analysis clearly showed that Saudi Arabia and Kuwait were grouped together because of a higher number of relevant published reports and prevalence of TB drug resistance. Interestingly, UAE had the highest prevalence of TB drug resistance. Low numbers of reports and of TB drug resistance were found for Oman, Qatar, and Bahrain; these countries were ultimately grouped together (Figure 3).

In order to protect the inhabitants of the Gulf countries and to ensure the medical status of expatriates for fit and free condition from infectious diseases, the Executive Board of the Health Ministers of GCC states created the GCC Approved Medical Centers Association (GAMCA) as the only medical services accredited to test and recommend migrant employees' work placements in the Gulf region [13]. To protect infected immigrants, GAMCA enforces screening for TB (chest radiograph) for all expatriates entering the region, and visas are granted only to individuals with no prior history of TB. In support, Ahamad et al. reported about automatic deportation for anyone suffering from pulmonary TB [14]. Keeping the TB burden in view, a comprehensive disease surveillance system for communicable diseases has been implemented in Oman [15]. Among all Gulf countries, Saudi Arabia is highly populated, yet there is a low number of reports from this country in comparison to the prevalence of drug resistance and MDR-TB [1]. Despite the alarming burden of TB/MDR-TB, only eight reports have been published from Kuwait, which demonstrates a complete lack of governmental policies towards management of TB drug resistance, scientific research, and a well-funded disease surveillance system equipped with trained healthcare professionals. For Saudi Arabia, WHO estimated that $1.4 \%-2.4 \%$ of new TB cases and nearly $10.8 \%$ of previously treated TB cases were MDR-TB [1]. Data retrieved from published studies of Saudi Arabia demonstrated that the pattern of resistance and prevalence rate of MDR-TB in last 10 years was $4.3 \%$ of the total infected population (Table 2); however, earlier studies reported $\sim 5.5 \%$ MDR-TB before 2000 
[16] and 4\% more recently [4]. There exists a strong proof-based opinion that the present status of MDRTB in Saudi Arabia is a result of historic clones of tubercle bacilli undergoing active circulation, and also of the huge migration of people from TB-endemic countries. Obligatory medical checking of millions of people visiting the country for religious purposes (Hajj and Umrah) is perhaps not a practically feasible idea $[10,17]$. This is a type of condition where models of herd immunity might be implemented and index case findings be aggressively followed. Such medical check-up needs may be considered as a key project for an MDR-TB control program and may be performed outside the country (at patients' homes) prior to their embarking upon the journey.

Weak and poor prognosis of MDR-TB in all the GCC members is partly due to insufficient laboratory support. Many laboratories under the National TB Control Program of Saudi Arabia lack the basic needs for bacteriological diagnostics of TB $[18,19]$. The practicability, viability, and cost-effectiveness of treatment of MDR-TB patients have been established in resource-limited settings [12,20,21]; Limitations that remain include the length of time required for some tests, the associated toxicity of presently recommended treatment regimens, and non-adherence leading to incomplete or failed treatment, all of which seriously obstruct the prognosis of increasing number of MDR-TB patients, especially in Saudi Arabia and Kuwait. The current findings indicate that recent developments in TB prevention and control in most of the GCC member states are idle except in Saudi Arabia and Kuwait. Keeping the current control and management situation of drug-resistant TB in the GCC region in view, it has been suggested that the treatment of MDR-TB should strictly adhere to WHO standards. The regulatory agencies of these GCC countries should require more thorough evaluation of potential combination regimens of new anti-TB drugs. New anti-TB or anti-MDR-TB drugs should be non-toxic, safe, efficacious, and properly tested in in vivo conditions [22]. Due to the limited availability of reports on MDR-TB from the GCC countries, we failed to conclusively determine the precise conversion rate of tuberculosis into MDR-TB. Also, due to the lack of a sufficient number of reports from GCC region against SLDs, we were unable to estimate the prevalence of XDR-TB in the Arabian Peninsular region (Table 2). The magnitude of this infectious disease is quite high in all the GCC countries as per the WHO data [1,9], which needs to be addressed in future studies for the substantial evaluation of the MDR-TB prevalence and control.

\section{Conclusions}

On the basis of the current findings, we can conclude that the prevalence of TB drug resistance in GCC member states is almost equivalent to other developing or developed countries. Isoniazid resistance was found to be the strongest predictor for the identification of MDR-TB in all the GCC countries. However, rifampicin was identified as a strongest predictor for the identification of MDR-TB in Oman, Kuwait, and Saudi Arabia. Due to fewer available isolates and reports, MDR-TB predictors for the remaining GCC countries could not be drawn. To improve the prevention and control of tuberculosis transmission and to decrease the rate of drug resistance in all the GCC states, possible measures include: enhanced antibiotic stewardship and decreased use of anti-TB drugs for non-TB conditions; standardization of practices and methods in the screening, diagnosis, and treatment of different forms of tuberculosis; and the employment of centralized reporting and accurate data collection. Heavy capital investment, creation of equipped laboratories, and procurement of well-trained staff is needed to implement the advanced technologies of testing of drug-resistant TB in all the GCC countries.

\section{Acknowledgements}

We thank Prof. Arif Ali (Gene Expression Laboratory, Department of Biosciences, Jamia Millia Islamia, New Delhi, India) for his critical scientific suggestions in analyzing and describing the data. The authors also thank to Jamia Millia Islamia (India) and Jazan University (KSA) for providing library and software program support for this study.

\section{References}

1. World Health Organization (2012) Global Tuberculosis Control Report. Geneva: World Health Organization. Available:

http://www.who.int/iris/bitstream/10665/75938/1/978924156 4502_eng.pdf. Accessed 5 April 2013.

2. Raviglione MC, Marais B, Floyd K, Lonnroth K, Getahun H, Migliori GB, Harries AD, Nunn P, Lienhardt C, Graham S, Chakaya J, Weyer K, Cole S, Kaufmann SH, Zumla A (2012) Scaling up interventions to achieve global tuberculosis control: progress and new 292 developments. Lancet 79: 1902-1913.

3. Dalton T, Cegielski P, Akksilp S, Asencios L, Caoili JC, Cho SN, Erokhin VV, Ershova J, Gler MT, Kazennyy BY, Kim HJ, Kliiman K, Kurbatova E, Kvasnovsky C, Leimane V, van der Walt M, Via LE, Volchenkov GV, Yagui MA, Kang H (2012) Prevalence of and risk factors for resistance to second- 
line drugs in people with multidrug-resistant tuberculosis in eight countries: a prospective cohort study. Lancet 380 Suppl 9851: 1406-1417.

4. Al-Hajoj S, Varghese B, Shoukri MM, Al-Omari R, AlHerbwai M, Alrabiah F, Alrajhi AA, Abuljadayel N, AlThawadi S, Zumla A, Zignol M, Raviglione MC, Memish Z (2013) Resistance in Saudi Epidemiology of Anti-tuberculosis Drug the First National Survey. Antimicrob Agents Chemother 57 Suppl 5: 2161-2166.

5. Zignol M, van-Gemert W, Falzon D, Sismanidis C, Glaziou P, Floyd K, Raviglione M (2012) Surveillance of antituberculosis drug resistance in the world: an updated analysis, 2007-2010. Bull World Health Org 90: 111-119D.

6. PressTV (2011) Jordan, Morocco to join [P] GCC. Available: http://www.presstv.ir/detail/179363.html. Accessed 5 May 2013.

7. Al-sharif A (2011) Gulf bloc to consider Jordan, Morocco membership. Available at http://news.xinhuanet.com/english2010/world/201105/11/c 13868474.htm. Accessed 27 April 2013.

8. Roberts L (2007) Yemen to join GCC by 2015. Arabian Business. Available: http://www.arabianbusiness.com/yemenjoin-gcc-by-2015-57086.html. Accessed 27 April 2013.

9. World Health Organization (2011) Global Tuberculosis Control Report. Geneva: World Health Organization. Available:

http://whqlibdoc.who.int/publications/2011/9789241564380 eng.pdf. Accessed 7 May 2013

10. Yezli S, Memish ZA (2012) Tuberculosis in Saudi Arabia: prevalence and antimicrobial resistance. J Chemother 24: 1-5.

11. Goble M, Iseman MD, Madsen LA, Waite D, Ackerson L, Horsburgh CR (1993) Treatment of 171 patients with pulmonary tuberculosis resistant to isoniazid and rifampin. $\mathrm{N}$ Engl J Med 328 Suppl 8: 527-532.

12. Tupasi T, Gupta R, Quelapio MaID, Orillaza RB, Mira NR, Mangubat NV, Arnisto VBN, Macalintal L, Arabit M, Lagahid JY, Espinal M, Floyd K (2006) Feasibility and cost-effectiveness of treating multidrug-resistant tuberculosis: a cohort study in the Philippines. PLoS Med 3: e352.

13. Khoja TAM (2010) Rules and regulations for medical examination of expatriates recruited for work in the GCC states. Riyadh: Executive Board of the Health Ministers' Council for Cooperation Council States Available: http://sgh.org.sa/Portals/0/PDF/Books/RulesAndRegulationFo rMedical.pdf. Accessed 10 May 2013.

14. Ahmad S, Fares E, Araj GF, Chugh TD, Mustafa AS (2002) Prevalence of S315T mutation within the katG gene in isoniazid-resistant clinical Mycobacterium tuberculosis isolates from Dubai and Beirut. Int J Tuberc Lung Dis 6: 920926.

15. World Health Organization (2010) Country cooperation strategy at a glance. Geneva: World Health Organization. Available

at:

http://www.who.int/countryfocus/cooperation_strategy/ccsbri ef omn en.pdf. Accessed 9 May 2013.

16. Alrajhi AA, Al-Barrak AM (2002) Mycobacterium tuberculosis susceptibility in Saudi Arabia. Saudi Med J 23: 1227-1231.

17. Alzeer AH (2009) Respiratory tract infection during Hajj. Ann Thorac Med 4: 50-53.
18. Alrajhi AA, Abdulwahab S, Almodovar E, Al-Abdely HM (2002) Risk factors for drug-resistant Mycobacterium tuberculosis in Saudi Arabia. Saudi Med J 23: 305-310.

19. Al-Hajoj S, Alrabiah F (2004) Role of tuberculosis laboratories in Saudi Arabia. A call to implement standardized procedures. Saudi Med J 25: 1545-1548.

20. Nathanson E, Lambregts-Vanweezenbeek C, Rich ML, Gupta $\mathrm{R}$, Bayona J, Blöndal $\mathrm{K}$, Caminero JA, Cegielski JP, Danilovits M, Espinal MA, Hollo V, Jaramillo E, Leimane V, Mitnick CD, Mukherjee JS, Nunn P, Pasechnikov A, Tupasi T, Wells C, Raviglione MC (2006) Multidrug-resistant tuberculosis management in resource-limited settings. Emerg Infect Dis 12: 1389-1397.

21. Resch S, Salomon J, Murray M, Weinstein M (2006) Costeffectiveness of treating multidrug-resistant tuberculosis. PLoS Med 3: e241.

22. D'Costa V, King C, Kalan L, Morar M, Sung W, Schwartz C, Froese D, Zazula G, Calmels F, Debruyne R, Golding GB, Poinar HN, Wright GD (2011) Antibiotic resistance is ancient. Nature 477 Suppl 7365: 457-461.

23. Al-Khal AL, Bener A, Enarson DA (2005) Tuberculosis among garment workers in an Arabian developing country: State of Qatar. Arch Environ Occup Health 60: 295-298

24. Khan FY (2009) Clinical pattern of tuberculous adenitis in Qatar: experience with 35 patients. Scand J Infect Dis 41 Suppl 2: 128-134.

25. Khan FY, Al-Muzrakchi AM, Elbedawi MM, Al-Muzrakchi AA, Al-Tabeb A (2012) Peritoneal tuberculosis in Qatar: a five-year hospital-based study from 2005 to 2009. Travel Med Infect Dis 10 Suppl 1: 25-31.

26. Al-Maniri A, Al-Rawas O, Al-Tuhami H, Eriksson B, Diwan VK (2007) Towards the elimination of tuberculosis in a developing country: 25 years of tuberculosis control in Oman. Int J Tuberc Lung Dis 11: 175-180.

27. Mohammadi A, Nassor ZS, Behlim T, Mohammadi E, Govindarajan R, Al-Maniri A. SmegoJr RA (2008) Epidemiological and cost analysis of multidrug-resistant tuberculosis in Oman. East Mediterr Health J 14 Suppl 6: 1240-1245.

28. Al-Maniri A, Singh JP, Al-Rawas O, Al-Busaidi S, AlBalushi L, Ahmed I, Al-Mahruqi S, Haile M, Diwan VK, Hoffner S (2010) A snapshot of the biodiversity and clustering of Mycobacterium tuberculosis in Oman using spoligotyping. Int J Tuberc Lung Dis 14: 994-1000.

29. Mokaddas E, Ahmad S, Abal AT (2002) Molecular fingerprinting of isoniazid-resistant Mycobacterium tuberculosis isolates from Chest Disease Hospital in Kuwait. Microbiol Immunol 46: 767-771.

30. Ahmad S, Mokaddas E (2005) The occurrence of rare rpoB mutations in rifampicin-resistant clinical Mycobacterium tuberculosis isolates from Kuwait. Int J Antimicrob Agents 26: 205-212.

31. Ahmad S, Jaber AA, Mokaddas E (2007) Frequency of embB codon 306 mutations in ethambutol-susceptible and -resistant clinical Mycobacterium tuberculosis isolates in Kuwait. Tuberculosis (Edinb) 87: 123-129.

32. Al-Mutairi NM, Ahmad S, Mokaddas E (2008) Performance of the genotype MTBDR assay for molecular detection of multidrug-resistant strains of Mycobacterium tuberculosis. Ann Saudi Med 28: 203-206. 
33. Mokaddas E, Ahmad S, Samir I (2008) Secular trends in susceptibility patterns of Mycobacterium tuberculosis isolates in Kuwait, 1996-2005. Int J Tuberc Lung Dis 12: 319-325.

34. Jaber AA, Ahmad S, Mokaddas E (2009) Minor contribution of mutations at iniA codon 501 and embC-embAintergenic region in ethambutol-resistant clinical Mycobacterium tuberculosis isolates in Kuwait. Ann Clin Microbiol Antimicrob 8: 2.

35. Al-Mutairi NM, Ahmad S, Mokaddas E (2011) Performance comparison of four methods for detecting multidrug-resistant Mycobacterium tuberculosis strains. Int J Tuberc Lung Dis 15: 110-115.

36. Ahmad S, Al-Mutairi N, Mokaddas E (2012) Variations in the occurrence of specific rpoB mutations in rifampicin-resistant Mycobacterium tuberculosis isolates from patients of different ethnic groups in Kuwait. Indian J Med Res 135: 756762.

37. Ahmad S, Fares E (2005) Genotypic diversity among isoniazid-resistant isolates of Mycobacterium tuberculosis from Rashid hospital in Dubai, United Arab Emirates. Med Princ Pract 14: 16-21.

38. Ahmad S, Itani LY, Fares E, Araj GF (2008) Varying prevalence of embB codon 306 mutations in ethambutolresistant clinical Mycobacterium tuberculosis isolates from Beirut and Dubai. J Chemother 20: 285-287.

39. Al-Zarouni M, Dash N, Al-Ali M, Al-Shehhi F, Panigrahi D (2010) Tuberculosis and MDR-TB in the northern emirates of United Arab Emirates: a 5-year study. Southeast Asian J Trop Med Public Health 41: 163-168.

40. Saif Alfaresi M, Hag-Ali M (2010) Susceptibility Pattern and Epidemiology of Mycobacterium tuberculosis in United Emirati Hospital. Open Microbiol J 4: 1-4.

41. Kordy FN, Al-Thawadi S, Alrajhi AA (2004) Drug resistance patterns of Mycobacterium tuberculosis in Riyadh, Saudi Arabia. Int J Tuberc Lung Dis 8: 1007-1011.

42. Al-Tawfiq JA, Al-Muraikhy AA, Abed MS (2005) Susceptibility pattern and epidemiology of Mycobacterium tuberculosis in a Saudi Arabian hospital: a 15-year study from 1989 to 2003. Chest 128: 3229-3232.
43. Al-Anazi KA, Al-Jasser A, Evans DA (2007) Infections caused by mycobacterium tuberculosis in patients with hematological disorders and in recipients of hematopoietic stem cell transplant, a twelve year retrospective study. Ann Clin Microbiol Antimicrob 6: 16.

44. Al-Hajoj S, Zozio AT, Al-Rabiah F, Mohammad V, AlNasser M, Sola C, Rastogi N (2007) First insight into the population structure of Mycobacterium tuberculosis in Saudi Arabia. J Clin Microbiol 45: 2467-2473.

45. Al-Shehri AM, Al-Ghamdi SM, Khalil A, Al-Amoudi, A, Baslaim A, Mamoun I (2007) Multi-drug-resistant tuberculosis in a patient presenting with bilateral gluteal abscesses and right leg swelling with end-stage renal disease. Saudi J Kidney Dis Transpl 18: 603-608.

46. Al-Qtabi F, Hazmi MMEI (2010) Extra-pulmonary tuberclorosis in Saudi Arabia. Indian J Pathol Microbiol 53: 227-231.

47. Asaad AM, Alqahtani JM (2012) Primary anti-tuberculous drugs resistance of pulmonary tuberculosis in Southwestern Saudi Arabia. J Infect Public Health 5: 281-285.

48. Varghese B, Hillemann A, Wijayanti DR, Shoukri M, AlRabiah F, Al-Omari R, Al-Hajoj S (2012) New insight into the molecular characterization of isoniazid and rifampicin resistant Mycobacterium tuberculosis strains from Saudi Arabia. Infect Genet Evol 12: 549-556.

\section{Corresponding author}

Dr. Shafiul Haque

Department of Biosciences, Faculty of Natural Sciences

Jamia Millia Islamia (A Central University)

New Delhi-110025, India

Phone \& Fax: +91-11-26988335

Email: shafiul.haque@hotmail.com

Conflict of interests: No conflict of interests is declared. 